\title{
A Long-Term Evaluation of Bone Levels Using Digital Scanning Radiographic Image Analysis on The CSC Telescopic Abutments in Severe Advanced Periodontitis Affected Secondary Occlusal Traumatism
}

\author{
Guey-Lin Hou ${ }^{1,2 *}$ \\ ${ }^{1}$ Former Professor, Graduate Institute of Dental Sciences, Department of Periodontics, and Periodontal Prosthetic Center, School of Dental Medicine, \\ Kaohsiung Medical University, Kaohsiung City, Taiwan
}

${ }^{2}$ Former Professor and Chairman, Dental Department, Periodontal Prosthetic Center, Chang-Gung Memorial Hospital, Kaohsiung City, Taiwan

Submission: August 19, 2021; Published: September 02, 2021

*Corresponding author: Guey-Lin Hou, Former Professor, Graduate Institute of Dental Sciences, Department of Periodontics, and Periodontal Prosthetic Center, School of Dental Medicine, Kaohsiung Medical University, Kaohsiung City, Taiwan

\begin{abstract}
The present study was to investigate the effectiveness of the CSC telescopic abutments using Sandwich's technique to treat individuals affected with severe advanced periodontitis (SAP) with secondary occlusal traumatism (SOT). A total of 66 abutments with both 26 molar abutments and 40 non-molar abutments, were treated at Dental Clinic of Kaohsiung Medical University Hospital. The mean age of individuals is ranged from 38 to 78 years old with a mean $54.77( \pm 19.19)$ years. The initial and cumulative radiographic periodontal bone levels of teeth affected SAP with SOT were calculated using an electronic digimatic caliper (EDC) and the digital scanning radiographic image analysis (DSRIA). The results showed that significantly improved RPBL after treatment. Both annual (ARPBL) were associated with IRPBL, but there was no relationship between cumulative (CRABL) and annual (ARABL) changes and the treatment periods. We can conclude that a difference of bone gain between both ERABL(\%), IRABL(\%) and ERABL(mm), IRABL(mm) was $9.46 \pm 12.01 \%$ as compared to $1.13 \pm 1.59 \mathrm{~mm}$. In addition, statistical analysis revealed a remark- able significant.
\end{abstract}

Keywords: Bone; CSC Telescopic Abutment; SAP; SOT; DSRIA

Abbreviations: SAP: Severe advanced periodontitis; SOT: Secondary occlusal traumatism; EDC: Electronic digimatic caliper; DSRIA: Digital scanning radio- graphic image analysis; FI: Furcation involvements

\section{Introduction}

Former literatures documented that periodontal therapy in the treatment of single-rooted teeth is simple and appeared to be better effective results. Majority studies documented that molar with furcation involvements (FI) seem to be more difficult as compared to that of molars without FI because of complicated furcation morphology and furcation entrance dimension. The clinical improvement of periodontal therapy is primary in the elimination of plaques and bacterial plaque toxins within the contaminated root surfaces providing a biologically acceptable environment where healing of the diseased periodontal tissues can take place [1]. Former studies documented that long-term and short-term results of periodontal therapy can provide beneficial effects in arresting the progressive destruction of periodontal diseases. In addition, it was also demonstrated that most remarkable improvement was reached at six months $[2,3]$. Little or limited literatures is available concerning the combined techniques of occlusal, periodontal, and prosthetic therapies was available using digital scanning radiographic image analysis (DSRIA) [4]. A recent study indicated that the effectiveness of the combined techniques of occlusal, periodontal, and prosthetic therapies entitled as "Sandwich's technique" to treat severe advanced periodontitis (SAP) with secondary occlusal traumatism (SOT) [5]. The present was to evaluate the initial, annual, and final radiographic periodontal bone levels ( ${ }^{*}$ IRPBL, \# FRPBL) of teeth affected SAP with SOT using an electronic digimatic caliper (EDC) and the digital scanning radiographic image analysis (DSRIA) [4]. 


\section{Advances in Dentistry \& Oral Health}

\section{Materials and Methods}

Study samples selected from a total of 66 abutments with both 26 molars (Figure 1a,1b) and 40 non-molar abutments (Figure 2a,2b), were treated at Dental Clinic of Kaohsiung Medical University Hospital. The mean age of individuals is ranged from 38 to 78 years old with a mean $54.77( \pm 19.19)$ years. The initial* and final\# radiographic periodontal bone levels (*IRPBL, \# FRPBL) of teeth affected SAP with SOT were calculated using an electronic digimatic caliper (EDC) and the digital scanning radiographic image analysis (DSRIA) (Figure 3). All the measurements were processed and analyzed by the computer system equipped with the MIS [6,7]. The flow chart of the CSCTD fabrication and treatment procedures demonstration were illustrated in Figure 4.

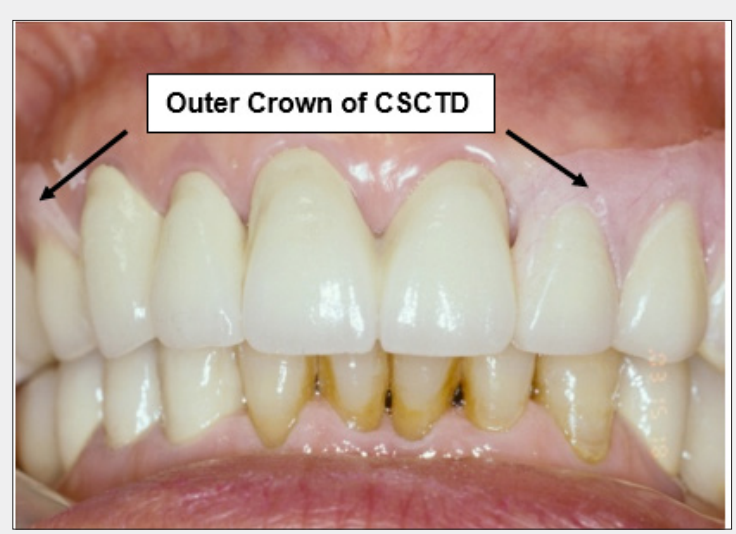

Figure 1a: shows labial appearance of CSCTD.

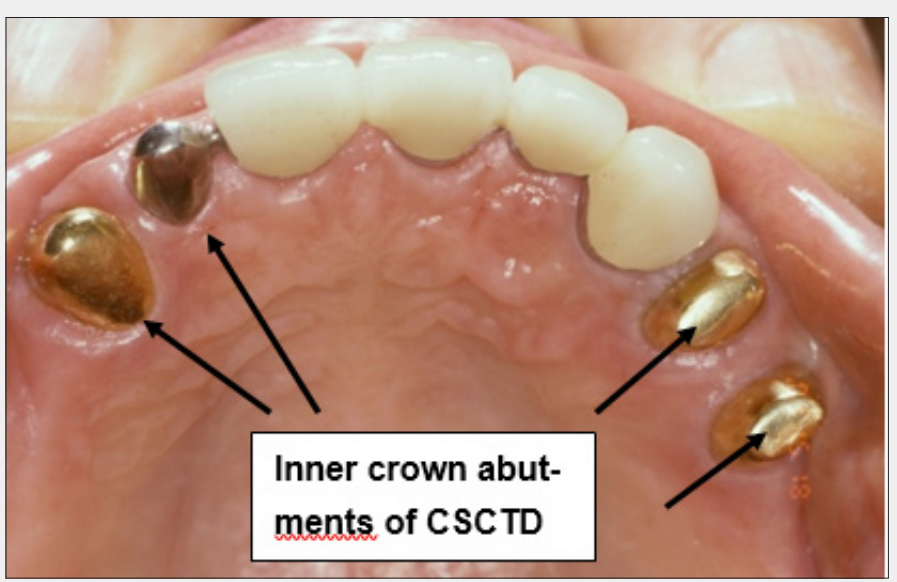

Figure 1b: shows palatal view of inner crowns of non-molar abutments of CSCTD.

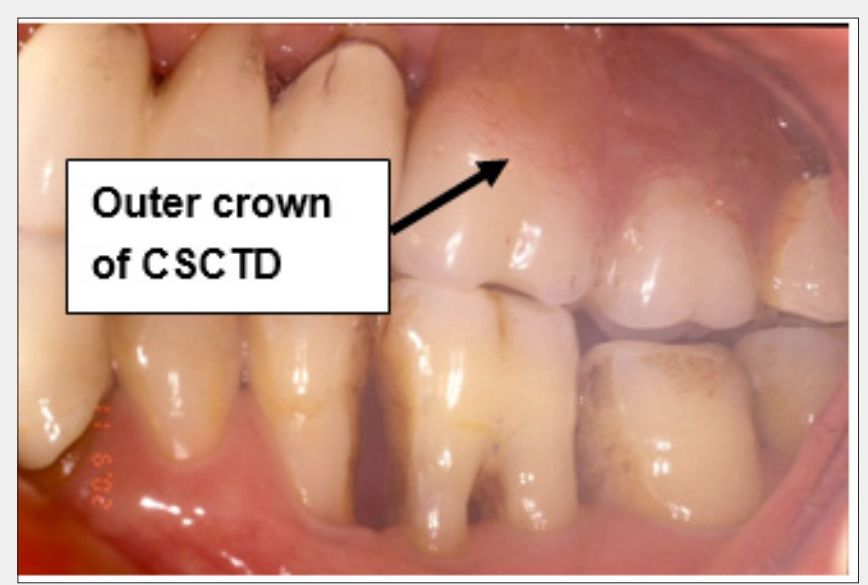

Figure 2a: shows the buccal view of outer crown of CSCTD. 


\section{Advances in Dentistry \& Oral Health}

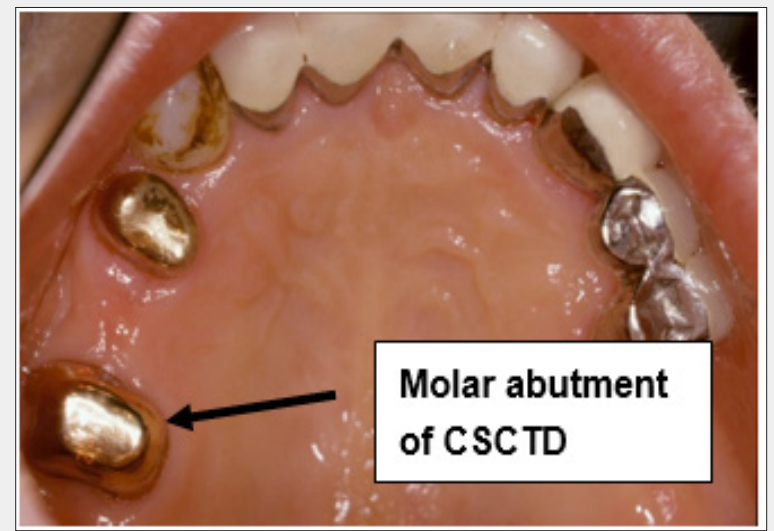

Figure 2b: shows the palatal view of inner crown of CSCTD.

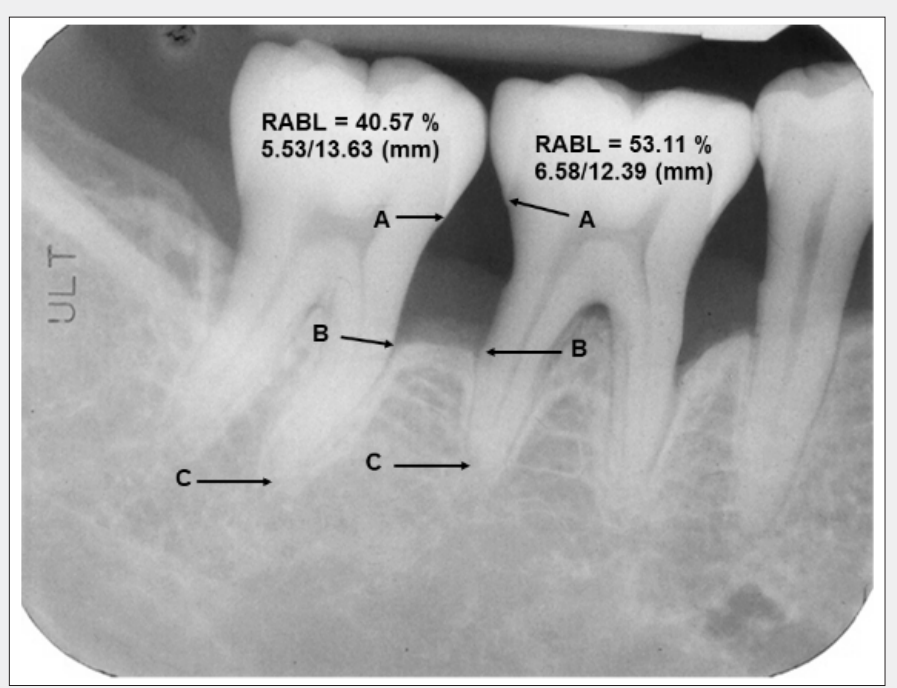

Figure 3: illustrates the radiographic periodontal bone levels of teeth affected SAP with SOT were calculated using an electronic digimatic caliper (EDC) and the digital scanning radiographic image analysis (DSRIA)[4]. ${ }^{*}$ Guey-Lin Hou: Advances in Dent \& Oral Health 2020;13 (4): 68-74.

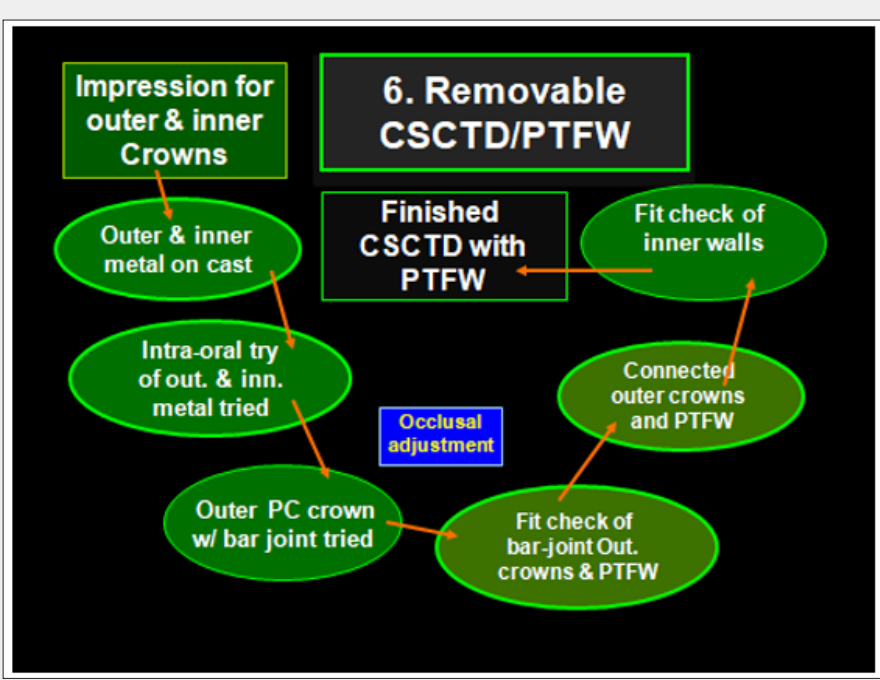

Figure 4: demonstrates the flow chart of the CSCTD fabrication. (PTFW: pure titalium framework; Out: outer; Inn: inner; PC: porcelain) 


\section{Results}

The results of comparative differences of IRBAL and ERABL using the Sandwich's technique in treating mesial and distal abutments of molars and non-molars affected angular bony defects were showed in Table 1 . In addition, results showed that significantly improved RABL after treatment. Both annual (ARPBL) were associated with IRPBL, but there was no relationship between cumulative (CRABL) and annual (ARABL) changes and the treatment periods. IRPBL and CRPBL changes of angular bony defects (ABD) in individuals affected SAP with SOT. It was concluded that:

Table 1: The comparative differences of IRBAL and ERABL using the Sandwich's technique in treating mesial and distal abutments of molars and non-molars affected angular bony defects.

\begin{tabular}{|c|c|c|c|c|c|}
\hline ABD & $\begin{array}{c}\text { Molar (26) } \\
\text { M(SD) }\end{array}$ & $\begin{array}{c}\text { Non-molar(40) } \\
\text { M(SD) }\end{array}$ & $\begin{array}{c}\text { Mesial(43) } \\
\text { M(SD) }\end{array}$ & $\begin{array}{c}\text { Distal(23) } \\
\text { M(SD) }\end{array}$ & $\begin{array}{c}\text { Total(66) } \\
\text { M(SD) }\end{array}$ \\
\hline $\begin{array}{c}\text { IRABL\% } \\
\text { M(SD) }\end{array}$ & $51.57(13.31)$ & $55.14(11.94)$ & $53.17(13.21)$ & $54.79(11.32)$ & $53.74(12.52)$ \\
\hline $\begin{array}{c}\text { CRABL\% } \\
\text { M(SD) }\end{array}$ & $63.99(13.06)$ & $62.68(13.21)$ & $61.53(12.66)$ & $66.32(13.52)$ & $63.19(13.07)$ \\
\hline $\begin{array}{c}\text { Differ. } \\
\text { M(SD) }\end{array}$ & $12.43(9.54)$ & $7.54(13.12)$ & $8.36(10.79)$ & $11.53(14.02)$ & $9.46(12.01)$ \\
\hline $\begin{array}{c}\text { Differ. } \\
\text { Range } \\
\text { (mm) }\end{array}$ & $-0.19 \sim 4.30$ & $-2.87 \sim 6.53$ & $-2.87 \sim 3.77$ & $-1.59 \sim 6.53$ & $-2.87 \sim 6.53$ \\
\hline $\begin{array}{c}\text { Differ. } \\
\text { M(SD) } \\
\text { (mm) }\end{array}$ & $1.33(1.11)$ & $0.99(1.83)$ & $0.97(1.37)$ & $1.44(1.92)$ & $1.13(1.59)$ \\
\hline $\begin{array}{c}\text { P value } \\
\text { Paired } \\
\text { t-test }\end{array}$ & $<0.0001$ & $<0.0008$ & $<0.0001$ & $<0.0007$ & $<0.0001$ \\
\hline
\end{tabular}

ABD: angular bony defect; N: CSC telescopic abutments; IRABL: initial radiographic alveolar bone level; CRABL: cumulative radiographic alveolar bone level; M (SD): mean (standard deviation); Differ: Difference.

a) There is an $8.36 \pm 10.79 \%$ and equal to $0.97 \pm 1.37 \mathrm{~mm}$ RABL gain of mesial surface at teeth affected ABD, and revealed a statistically significant $(\mathrm{p}<0.0001)$ improvement

b) Where there is a remarkably and significant RABL gain $(11.53 \pm 14.02 \%$ as compared to $1.44 \pm 1.92 \mathrm{~mm}$ ) of distal surface at teeth affected $\mathrm{ABD}$, respectively.

Results also indicated that there is a $7.54 \pm 13.12 \%$ as compared to that of $0.99 \pm 1.83 \mathrm{~mm}$ RABL gain on the Non-molar teeth affected $A B D$, a significant $(p<0.0008)$ improvement of bone gain was noted. Similarly, there was a remarkable bone gain on the molars affected ABD with a $12.43 \pm 9.54 \%$ and that of a $1.33 \pm 1.11 \mathrm{~mm}$ and showed a statistically significant $(\mathrm{p}<0.0001)$. As mentioned above, we can concluded that a difference of bone gain between both CRABL(\%), IRABL (\%) and CRABL(mm), IRABL(mm) was 9.46 \pm $12.01 \%$ as compare to $1.13 \pm 1.59 \mathrm{~mm}$ and a remarkable significant ( $p<0.0001$ ) was found.

\section{Discussion}

The flowchart of the Sandwich's technique in treating teeth affected SAP with severe angular bony loss and higher mobility are a summary as follows;

i. $\quad$ Phase I periodontal therapy including scaling and root planning and maintain therapy or the mean of non-surgacal periodontal therapy (NSPT) ii. Phase II periodontal therapy is immobilization of hypermobile teeth with secondary occlusal traumatism (SOT) using therapeutic provisional prosthesis

iii. Non-surgical root separation and/or root resection (RS/ RR) for molar with advanced Class III molar furcation

iv. Fixed prosthesis and/or crown and sleeve-coping telescopic denture (CSCTD) prosthesis, or both [5].

Former reported data in some literatures documented that NSPT might be not only improve clinical periodontal parameters but can also resolve and arrests periodonitis [8-11]. In addition, the other studies [12-15] also reported that deep probing pocket depths (PPD) within the molar furcation involvements are prone to more clinical attachment loss, and an increased mortality rate when observed over years. Conflicting data were reported concerning the bone fills of angular gain of angular bony defects following surgical and non-surgical periodontal therapy. Renvert et al. [16] demonstrated that limited repaired often occurred in the treatment of intra-osseous defects with flap operation, and there was virtually no bone fill after root planning. In contrast, the findings of minimal bone fills after scaling and root planning were different from the findings reported by both Rosling et al. [17] and Polson \& Heijl [18] that an abundant bone fills occurred after flap operation. 
Little or limited data of literatures concerning the combined use of NSPT, TPP, CSCTD and/or fixed prosthesis, also former article entitled "the Sandwich's technique" $[5,11,19,20]$. The present study documented the major discrepancy concerning molar prognosis was focused on the high prevalence of complications, such as root morphology, recurrence of furcation lesions, poor plaque control over the internal root concavity, and inconclusive treatment modalities. Our earlier report indicated a remarkable clinical improvement in advanced furcation invasion cases after RSR and/or RR therapy compared to those exclusively using CSCTD [20]. The conclusions of the study were further showed by clinical evaluation. Especial concerning the comparative differences of both IRABL and FRABL assay, that employed the Sandwich's technique included TPP, NSPT, fixed prosthesis and/ or CSCTD therapies, to treat both non-molars and molars of SAP with SOT affected angular bony defects, good periodontal healing, occurred at the mesial and distal surfaces.

\section{References}

1. Ramfjord SP (1980) Root planning and curettage. Intern Dent J 30(2): 93-100.

2. Philtrom BL, Ortiz-Campos, McHugh RB (1981) A randomized fouryear study of periodontal therapy. J Periodontol 52(5): 227-242.

3. Wesfeld E, Bragd L, Socransky SS (1985) Improved periodontal conditions following therapy 12(4): 283-293.

4. Hou GL, Hung CC, Tang YS (2003) Radiographic alveolar bone loss in untreated Taiwan Chinese subjects with adult periodontitis measure by digital scanning radiographic image analysis method. Dentomaxillofac Radiology 32(2): 104-108.

5. Hou GL, Hou LT (2019) Therapeutic outcomes using the Sandwich's technique in treating severe advanced periodontitis with secondary occlusal trauma: a long-term study. Intern J Dentistry and Oral Health 5(7): 76-85

6. Hou GL, Lin CH, Hung CC, Yang YS, Shieh TY, et al. (2000) The consistency and reliability of periodontal bone level measurements using digital scanning radiographic image analysis - A pilot study. Kaohsiung J Med Sci 16: 566-573.

7. Hou GL (2020) Digital scaning radiographic image analysis of alveolar bone loss in individuals with untreated adult Periodontitis and aggressive periodontitis. A crosssetional study. Adcances in Dent \& Oral Health 13 (4): 68-74.

8. Muller HP, Eger T, Langer DE (1995) Management of furcation-involved teeth - a retrospective analysis. J Clin Periodontol 22(12): 911-917.

9. Yukna RA (1992) Clinical human comparison of expanded polytetrafluoro-ethylene barrier membrane and freeze-dried dura mater allografts for guide tissue regeneration of lost periodontal support. I. Mandi- bular molar Class II furcation. J Periodontol 63(5): 431-442.

10. Bowers RC (1979) Furcation morphology relative to periodontal treatment: Furcation root surface anatomy. J Periodontol 50(7): 366374.

11. Hou GL, Chen SF, Wu YM (1994) The topography of the furcation entrance in Chinese molars. Furcation entrance dimensions. J Clin Periodontol 21(7): 451- 456.

12. Ramfjord SP (1980) Root planning and curettage. Intern Dent J 30(2): 93-97.

13. Hirshfeld L, Wasserman B (1978) A long-term survey of tooth loss in 600 treated periodontal patients. J Periodontol 49(5): 225-237.

14. McFall, WT (1982) Tooth loss in 100 treatment patients with periodontitis disease: a long-term study. J Periodontol 53(9): 535-549.

15. Hou Gl, Tsai CC (1987) Relationship between periodontal furcation involvement and molar cervical enamel projection. J Periodontol 58(10): 715-721.

16. Renvert S, Badersten A, Nilveus R (1981) Healing after treatment of periodontal intra-osseous defects. I. Comparative study of clinical methods. J Clin Periodont 3: 387-53.

17. Rosling B, Nyman S, Lindhe J (1976) The effect of systematic plaque control on bone regeneration in infra-bony pockets. J Clin Periodontol $3(1): 38-53$

18. Polson AM, Heijl LC (1978) Osseous repair in infra-bony periodontal defects. J Clin Periodontol 5(1): 13-23.

19. Hou GL, Tsai CC, Weisgold AS (1999) Treatment of molar furcation involvement using root separation and a crown and sleeve-coping telescopic denture - A longitudinal study. J Periodontol 70(9): 10981109.

20. Hou GL (2020) Clinical application of CSC telescopic denture with magnetic attachment in treating Class III molar furcation involvementA case report. Intern J Dent and Oral Health 6(6): 1-4.

\begin{tabular}{l} 
Your next submission with Juniper Publishers \\
will reach you the below assets \\
- Quality Editorial service \\
- Swift Peer Review \\
- Reprints availability \\
- E-prints Service \\
- Manuscript Podcast for convenient understanding \\
- Global attainment for your research \\
- Manuscript accessibility in different formats \\
( Pdf, E-pub, Full Text, Audio) \\
- Unceasing customer service \\
Track the below URL for one-step submission \\
https://juniperpublishers.com/online-submission.php \\
\hline
\end{tabular}

